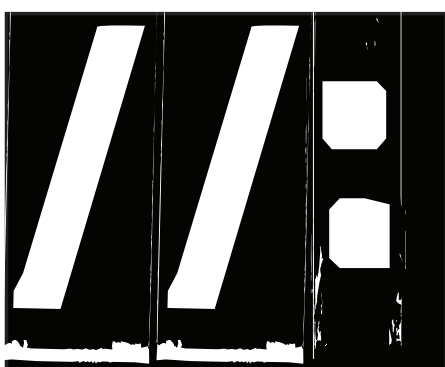

aducación y cömunicación 6: 119-127 Mayo 2013

\title{
DIVULGACIÓN CIENTÍFICA EN TELEVISIÓN: RIGOR Y ENTRETENIMIENTO
}

\section{Disseminating Scientific through Television: Rigor and Entertainment}

\author{
José María Montero Sandoval \\ E-mail: sandoval@arrakis.es \\ Periodista y miembro de la Academia \\ de las Ciencias y las Artes de Televisión. \\ Director de "Espacio Protegido". \\ Canal Sur Televisión. Sevilla (España)
}

\section{Resumen:}

Desde 2002, la Estación Biológica de Doñana (CSIC) y la Radio Televisión de Andalucía (RTVA) vienen colaborando en el desarrollo y difusión de expediciones científicas a diferentes espacios naturales que, más allá de la Península Ibérica, mantienen algún vínculo ecológico con nuestro país. De esta manera, y en una experiencia pionera en España, un equipo de televisión ("Espacio Protegido", Canal Sur TV) filma, en tiempo real, los avatares de un viaje de estas características, rodeado de dificultades pero, también, abierto a sorprendentes descubrimientos científicos. Aventura y rigor no son valores incompatibles en este producto televisivo.

Palabras clave: Divulgación científica, televisión, educación ambiental, periodismo ambiental.

\section{Abstact:}

Since 2002, the Biological Station of Doñana (CSIC) and Radio Televison Andalucia (RTVA) and been in collaboration in the development of the dissemination of distinct scientific expeditions to those natural areas that have an ecological tie with Spain. In this pioneering initiative, the film crew of "Espacio Protegido" from Canal Sur Television have filmed in real time distinct programmes of this nature, and the outcome of these programmes has brought about surprising scientific discoveries. Adventure and rigorous science, in this respect, are not incompatible in a television programme.

Key words: Scientific dissemination, television, environmental education, environmental journalism.

Recibido: 21-01-2013 / Revisado: 10-02-2013 / Aceptado: 14-03-2013 / Publicado: 01-05-2013

https://dx.doi.org/10.25267/Hachetetepe.2013.v1.i6.10 


\section{II: Educación ambiental y fotografía}

\section{Introducción}

L a alianza, o la simple complicidad, entre científi-

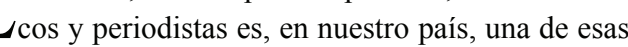
rarezas que hipotecan la divulgación científica a gran escala. La queja hace tiempo que se viene expresando en diferentes foros, como advertían Emilio Muñoz y Marta Plaza, especialistas de la Unidad de Políticas Comparadas del Consejo Superior de Investigaciones Científicas, al considerar que "la eficiencia de los medios de comunicación, como vehículo de la información científico-técnica, es muy reducida”. Así las cosas, sugerían Muñoz y Plaza, se impone "una mejora en la calidad y cantidad de la información, tarea que requiere fomentar la interacción y cooperación entre diferentes actores, con distintas capacidades y objetivos: en nuestro caso, medios de comunicación, instituciones de investigación, periodistas y científicos" (1).

Lo paradójico de este desencuentro es que en ambos colectivos, científicos y periodistas, se manifiestan necesidades cuya satisfacción podría resolverse, en gran medida, con el establecimiento de esa, hasta ahora, rara alianza. Los científicos necesitan divulgar sus interrogantes, sus retos, la utilidad social de su trabajo, sus problemas, las respuestas que han sido capaces de iluminar,... Necesitan socializar las incertidumbres que habitan en la investigación, para que ésta pueda ser entendida en sus justos términos. Precisan, como no había ocurrido hasta ahora, de un respaldo social que, a la postre, se traduzca en un decidido respaldo político, que es del que nacen los recursos, materiales o financieros, que requieren. En definitiva, necesitan escapar de los círculos endogámicos en los que, con demasiada frecuencia, se refugian, y salir así a la calle y explicar, y explicarse, ante los ciudadanos.
Los periodistas, por nuestra parte, estamos necesitados de noticias, de novedades, de descubrimientos, de aventuras, de esfuerzos titánicos, de misterio,... ¿Y no son éstos los materiales con los que a menudo, por no decir siempre, se teje la actividad científica? En una sociedad cada vez más tecnificada, cada vez más vinculada al hecho científico y sus consecuencias en la vida cotidiana, necesitamos contar esa nueva, y poderosa, dimensión de nuestra realidad. Y contarla, eso sí, de manera atractiva, de forma que pueda ser comprendida por aquellos para los que la Ciencia es un territorio oscuro, complejo e intraducible, sin traicionar, al mismo tiempo, el rigor con el que se construyen los materiales de la Ciencia.

Si estamos condenados a entendernos, ¿por qué no nos entendemos? Muñoz y Plaza señalan una parte del problema cuando afirman que "la actividad de divulgación por parte de la comunidad científica se enfrenta a resistencias internas para su promoción y reconocimiento en su disciplina, al no concederse dentro de la profesión científica aún a la divulgación la importancia que merece, no en detrimento de la investigación seria y de excelencia, sino como parte integrante de cualquier tipo de actividad científica que debe dar a conocer sus frutos a la sociedad" (2). Pero ésta, como digo, es sólo una parte del problema, porque también habría que referirse, por ejemplo, a la desconfianza mutua y sus variopintas manifestaciones.

Cuando el científico tiene que exponer sus conocimientos en un medio de comunicación no especializado, usando como intermediario a un periodista, no es descabellado asegurar que alguna, o todas, de las siguientes ideas le rondan en la cabeza, provocando una inquietud que puede convertirse en miedo:

- No van a ser rigurosos.

- Van a banalizar lo trascendente y van a 


\section{1/: Divulgación científica en televisión:}

destacar lo accesorio.

- Van a convertir en superficial lo complejo.

- Van a ofrecer certezas a partir de mis incertidumbres.

- Van a desvirtuar mi mensaje poniendo incluso en entredicho mi cualificación (van a caricaturizar la Ciencia).

- Van a convertir mis conocimientos en una "toma de postura" que se asocie a una opción política o a una corriente de opinión.

El periodista, en idéntica situación, también tiene miedo de los científicos:

- Se van a centrar en aspectos poco atractivos para el gran público.

- No van a saber, ni querer, vulgarizar sus conocimientos, de manera que cualquiera pueda entenderlos.

- Su lenguaje será indescifrable.

- Necesitarán mucho más espacio o tiempo del que dispongo para exponer sus conocimientos.

- Me plantearán tantas incertidumbres y tantas cautelas que al final no tendré noticia.

- Terminará siendo una información gris y compleja para públicos exquisitos.

\section{Expediciones}

En la mayoría de los casos poco hacen unos y otros para acercar posiciones, para entender al contrario, para saber de sus miedos y dificultades y buscar así la manera de salvarlas. Y en este esfuerzo por construir una alianza honesta es, justamente, en el que nos embarcamos, hace ya unos cuantos años, los periodistas que trabajamos en el programa "Espacio Protegido"

\section{Divulgatio}

(Canal 2 Andalucía) y los investigadores de la Estación Biológica de Doñana (EBD - CSIC). Después de más de una década de intensa relación que, lógicamente, había derivado en una notable confianza mutua, en 2002 decidimos dar un paso adelante y plantear una experiencia pionera en nuestro país. Científicos y periodistas nos hicimos la siguiente pregunta: ¿seremos capaces de producir, mano a mano y en igualdad de condiciones, materiales y herramientas de divulgación que sean valiosas para ambos? $\mathrm{O}$, dicho de otra manera, ¿podemos elaborar productos de divulgación científica que sean atractivos desde el punto de vista televisivo y que, al mismo tiempo, sean rigurosos y puedan resultar de utilidad para los científicos? Y para resolver estos interrogantes acordamos un territorio común en el que buscar las respuestas, un territorio en el que, a priori, ambos nos sintiéramos cómodos. Ese territorio resultaron ser las expediciones científicas, por utilizar un término que todo el mundo identifica con facilidad, aunque en realidad se trate de esos viajes, casi cotidianos, que los científicos de la EBD deben realizar a distintos puntos del planeta para resolver sus proyectos de investigación.

Seleccionamos, de mutuo acuerdo, aquellos viajes que combinaran el interés de la propia actividad científica que se iba a desarrollar en los mismos con otros elementos capaces de enriquecer el discurso televisivo (la variedad de los trabajos a ejecutar, el vínculo con fenómenos o problemas presentes en España, la cooperación con otros investigadores foráneos o el propio atractivo de los escenarios naturales en donde se iba a trabajar). Creamos, y aquí está el elemento más novedoso y arriesgado de la experiencia, un equipo mixto de trabajo, de tal manera que renunciamos al modelo tradicional (un equipo de televisión que documenta, 


\section{II: Educación ambiental y fotografía}

mirando desde el exterior, el trabajo de los científicos de acuerdo a sus indicaciones) y acordamos una fórmula en la que todos trabajáramos, mano a mano y en igualdad de condiciones, desde el principio hasta el final, desde el propio diseño del viaje hasta la redacción y montaje de los guiones finales.

Se trataba, en definitiva, de documentar las expediciones tal cual, desde dentro, en tiempo real, en las mismas condiciones en que estas se desarrollaban, sin teatralizar, sin evitar las dificultades, asumiendo los tiempos muertos, las duras condiciones de vida, los fracasos... Aprovechando las sorpresas que pudieran surgir y haciendo de las dificultades de un rodaje de estas características un elemento más que pudiéramos aprovechar como "materia prima". Fieles a estos principios, también renunciamos a desplazar un gran equipo humano o a dotarnos de sofisticados sistemas de grabación.

La iniciativa, a la que en 2006 se sumó el Parque de las Ciencias de Granada, se ha materializado, hasta la fecha, en cuatro series documentales (3):

\section{Expedición a Kazajistán (junio 2003).}

El equipo de periodistas y científicos se estrenó, en junio de 2003, con un viaje a las estepas de Kazajistán. El resultado de aquella experiencia se plasmó en la serie documental "El jardín de los vientos", compuesta por tres capítulos de 30 minutos cada uno, emitida en Canal Sur TV en diciembre de 2003.

\section{Expedición a Mauritania-Senegal (diciembre 2004).}

El segundo viaje, que ocupó buena parte del mes de diciembre de 2004, tuvo como escenario algunos de los espacios naturales más sobresalientes de Mauritania y Senegal. La experiencia se plasmó en la serie documental "Mauritania: tres colores", compuesta por tres capítulos de 30 minutos cada uno, emitida en Canal Sur TV en abril de 2005.

\section{Expedición a Argentina (noviembre, 2006).}

En noviembre de 2006 se completaba el tercer capítulo de esta singular colaboración entre científicos y comunicadores. Argentina fue el destino elegido. A los dos socios originales (EBD RTVA) se sumó en esta ocasión el Parque de las Ciencias de Granada.

La experiencia se plasmó en la serie documental "El sur infinito", compuesta por dos capítulos de 50 minutos cada uno, emitida en Canal Sur TV en abril de 2007.

\section{Expedición a Australia-Tasmania (abril y di- ciembre, 2009)}

El siguiente capítulo de esta colaboración tuvo como escenario Australia-Tasmania. El rodaje se desarrolló en los meses de abril y diciembre de 2009. La serie "Planeta Australia" se dividió en dos capítulos de 50 minutos que se emitieron en Canal Sur TV en octubre de 2009 y junio de 2010.

\section{Herramientas}

Las herramientas de las que disponemos para llevar a cabo nuestro trabajo no son muy sofisticadas. Des- 


\section{1/: Divulgación científica en televisión:}

plazamos un equipo convencional de televisión, en formato profesional, al que sólo se añade, en algunos casos, una óptica especial para filmar a gran distancia sin interferir en la actividad de algunos animales. Como es lógico, tanto el director-guionista del equipo como los técnicos que lo componen (realizador y operador de cámara) son especialistas en divulgación científica con amplia experiencia en este tipo de producciones.

Al mismo tiempo, y aunque pudiera parecer un elemento innecesario frente a las cualidades de la televisión, en todas estas expediciones nos ha acompañado un fotógrafo profesional, también especializado en fotografía científica. ¿Qué ventajas adicionales nos ha proporcionado esa herramienta? Por un lado ha servido para documentar todo el trabajo de los expedicionarios, creando un banco de imágenes, de alta calidad, muy útil a la hora de enriquecer publicaciones (tanto en papel como electrónicas) relacionadas con esta iniciativa. Asimismo, las fotografías han servido para componer algunos de los elementos educativos generados a partir de las expediciones (conferencias, exposiciones itinerantes, proyecciones en centros educativos, guías didácticas, etc...).

La televisión, en las circunstancias en las que se ha desarrollado el trabajo, se ha detenido, sobre todo, en el "plano general", en el escenario más global del trabajo científico, en las acciones y la palabra, en su contexto, sus protagonistas, sus dificultades, sus resultados... La fotografía, por el contrario, ha puesto el acento en los detalles, ha servido para congelar un momento decisivo, un elemento que por su propia naturaleza (fugacidad, tamaño, mimetismo) hubiera pasado inadvertido. Palabra escrita y locutada, sonido ambiente, imagen en movimiento y fotografía estática

\section{Divulgatio}

son todos los elementos que, finalmente, se han combinado en este producto atípico.

\section{Conclusiones}

En lo que se refiere estrictamente a su dimensión televisiva, el proyecto, y su desarrollo a lo largo de una década, nos ha servido para cuestionar, con el valor de la experiencia, algunos de los mitos que giran en torno a los documentales de naturaleza:

\section{Potencia no equivale a efectividad.}

Las grandes producciones, los documentales de élite, no siempre son tan efectivos como pudiera pensarse, ni para la Ciencia, ni para la propia televisión ni para los espectadores.

Muchos de estos documentales de naturaleza están encorsetados en un esquema formal que empieza a parecernos caduco, un planteamiento que apenas se ha revisado en los últimos treinta años. Un relato monótono, poco atrevido en su realización y desarrollo, y descaradamente antropocéntrico. Con frecuencia prima el discurso puramente estético (animales o paisajes sorprendentes), o la atención se concentra (o se dispersa, según como se mire) en las llamativas técnicas de rodaje. Cuando podemos contemplar, en primerísimo primer plano, el majestuoso vuelo de un buitre son más los espectadores (porque ese es el sentido que se ha buscado en la secuencia) que están preocupados en saber cómo se han podido filmar dichas imágenes que los que de verdad se interesan por las características o la situación de la especie.

Este tipo de documentales aportan prestigio a las parrillas de televisión, pero con frecuencia sus índices de audiencia nos revelan un cierto cansan- 


\section{II: Educación ambiental y fotografía}

cio y hasta aburrimiento por parte de la audiencia. Suelen ser excelentes manuales de historia natural, pero se olvidan del contexto en el que se desarrollan las acciones (porque así pueden circular con soltura en un mercado globalizado), prescinden del compromiso (su neutralidad llega a resultar forzada), renuncian al atrevimiento formal (alejándose de los códigos audiovisuales que hoy atraen a los espectadores más jóvenes), y por eso, finalmente, no tienen alma (esa carga afectiva que nos ayuda a interesar a los públicos no especializados, un recurso que, por ejemplo, manejó con maestría Félix Rodríguez de la Fuente).

\section{La televisión no siempre implica complejidad.}

Cuando se plantea una producción televisiva cuya finalidad es mostrar un trabajo de investigación ambicioso que, además, se desarrolla en escenarios remotos y en condiciones adversas, suele pensarse que dicha producción va a exigir recursos muy complejos y caros. Imaginamos, como imprescindibles, cámaras de alta resolución, ópticas especiales o micrófonos ultrasensibles. Equipos de trabajo compuestos por un sinfín de técnicos. Planes de rodaje que se extienden a lo largo de varios meses o años. Sofisticadas labores de postproducción, y la logística propia de un ejército.

Uno de los grandes fotógrafos del siglo XX, Henri Cartier-Bresson, usó una única óptica $(50 \mathrm{~mm})$ para la mayor parte de su obra. Su ejemplo puede trasladarse a la televisión: ¿qué es más importante, la herramienta con la que se mira o la propia mirada?

Con medios y presupuestos modestos también se puede hacer televisión de calidad, también es posible abordar documentales de naturaleza. "Crecer en exceso es decaer", dice la máxima taoísta, y la decadencia de ciertos formatos televisivos se explica, precisamente, por ese afán que nos lleva a disponer de recursos casi ilimitados.

Además de los modestos equipos que hemos utilizado, también nos esforzamos por resolver el montaje de los documentales en un tiempo record, para convencernos de que son calendarios asumibles por una televisión pública dentro de sus esquemas de producción propia.

\section{La televisión no siempre banaliza cualquier contenido.}

Asegura Woody Allen que nunca entendió a los que afirman que la televisión jamás ha hecho nada por la Cultura, puesto que él, cada vez que la enciende, siente el inmediato deseo de leer un libro. No es justo considerar que la televisión banaliza cualquier contenido. No es cierto que la televisión sea incapaz de profundizar, de reflexionar, de explicar lo complejo de forma rigurosa y honesta. Hay numerosos ejemplos que desdicen este prejuicio, y nosotros hemos querido contribuir a ese esfuerzo por dignificar un medio de comunicación que, con frecuencia, sólo recibe críticas.

\section{La fascinación por lo lejano se puede trasladar al ámbito doméstico.}

El interés y la credibilidad de los trabajos televisivos, y periodísticos en general, son valores sometidos a perversas rutinas. Por ejemplo, ésa que tiene que ver con la distancia, la extraña fascinación que lo lejano ejerce en los mass media. Lo 


\section{1/: Divulgación científica en televisión: Rigor y entretenimiento}

que ocurre a miles de kilómetros de nuestro hogar, ya lo sabemos, suele tener para los periodistas un atractivo irresistible. Las novedades que en cualquier campo del conocimiento puede aportar un humilde departamento universitario de nuestro entorno más inmediato acostumbran a tener menos morbo mediático que las intrascendentes aportaciones de un exótico centro de investigación localizado en un remoto país.

En nuestra experiencia con la EBD no renunciamos a esa fascinación, y por eso viajamos a territorios remotos, pero en esos escenarios ya habíamos identificado elementos que nos remitían a nuestro entorno más inmediato. Nos marchamos muy lejos para explicar lo que sucede en nuestra misma casa. Tenemos aquí las preguntas y allí las respuestas. En definitiva, aplicamos, de alguna manera, ese concepto tan ecológico de que todo está relacionado con todo. Y la explicación, y las reflexiones, venían de la mano de investigadores españoles, no de un exótico centro de investigación localizado a miles de kilómetros.

En Kazajstán los científicos trataban de analizar, entre otras cuestiones, cómo son las estepas vírgenes, las estepas que no han sufrido el impacto de la humanización. Así es posible precisar el estado de conservación de nuestras propias estepas, alteradas, desde hace siglos, por la mano del hombre. ¿Qué hemos perdido en este tránsito? Sólo podemos saberlo conociendo lo que aún pervive en aquellos espacios similares e inalterados.

En Mauritania seguimos a un alimoche, nacido en tierras gaditanas, en su largo viaje migratorio hasta las orillas del Sahara. En este caso, cabía preguntarse qué ocurre con estos animales cuan-
Divulgatio

do abandonan Europa, dónde reciben protección, y se instalan en tierras africanas. ¿Tiene sentido invertir importantes sumas de dinero en la conservación de la especie ignorando, al mismo tiempo, lo que ocurre con ella una vez que migra? ¿Qué relación existe entre la supervivencia de este animal en África y las difíciles condiciones de vida que se registran en los países del Sahel?

En Argentina las preguntas, esas que vinculan territorios muy alejados entre sí, fueron similares. Cuando nos sorprende la rica biodiversidad marina que atesora el santuario de Península Valdés y consideramos justificada la estricta protección que allí se brinda a ballenas o pingüinos, ¿sabemos qué grado de responsabilidad tienen los mercados españoles en la conservación de estos espacios? ¿Cuál es el impacto de la pesca intensiva, en manos de empresas españolas, en estos ecosistemas?

Y, por último, en Australia tuvimos ocasión de explicar uno de los grandes problemas ambientales de aquel país-continente que también tiene conexiones con Andalucía: la proliferación del conejo. Esta especie, introducida por los primeros colonos, ha causado un auténtico desastre ambiental en las antípodas. En Andalucía, por el contrario, el descenso en las poblaciones de conejo está resultando fatal para especies muy valiosas que de él se alimentan, como el lince o el águila imperial. Investigadores australianos y andaluces comparten sus conocimientos sobre la especie para aplicarlos en estrategias de conservación contrapuestas: unos tratan de eliminarlo y otros de conservarlo.

Son sólo cuatro ejemplos, porque en cada viaje 


\section{II: Educación ambiental y fotografía}

tratamos de responder a muchas más preguntas, pero en ellos se hace compatible esa fascinación por lo lejano y la necesidad de explicar lo que ocurre en nuestro ámbito doméstico.

\section{El rigor no implica aburrimiento.}

La ciencia, como escribía al comienzo de este texto, tiene mucho de aventura, de acción y de misterio, y esos son elementos muy valiosos en televisión. Se puede divulgar la Ciencia, sin traicionar el rigor y sin caer en el aburrimiento. Existe una Ciencia para todos los públicos pero hay que saber cómo contarla aprovechando, al máximo, los recursos que brinda el medio televisivo.

Hemos tenido la suerte, aunque sea una suerte que nace del compromiso y el esfuerzo, de acompañar a científicos que son excelentes comunicadores, que son capaces de amoldarse al lenguaje televisivo sin perder rigor. Científicos que no tienen miedo de revelar los entresijos de su trabajo, de desmitificar su labor, de mostrarse como personas, normales y corrientes, que hablan a otras personas, normales y corrientes. Así, hemos tratado de humanizar los trabajos de investigación, haciendo de sus autores unos protagonistas de carne y hueso, sesudos pero también divertidos.

Rigor no significa envaramiento formal. Hemos mostrado el trabajo científico, pero también nos hemos introducido en la propia peripecia del viaje, en la convivencia diaria entre científicos y comunicadores, en la interacción con los hombres y mujeres que pueblan los territorios visitados. Con frecuencia estos últimos, sin ser especialistas, han sabido relatar, con valiosos tintes afectivos y una llamativa precisión, las características y los valores de un determinado enclave.
La televisión de nuestros días es, sobre todo, un negocio, donde las leyes de mercado pesan más que el compromiso informativo. El desaparecido Riszard Kapuscinski expresa este mismo lamento en una obra fundamental (4) para todos aquellos que pelean por dignificar este oficio. Los medios de información -advertía el periodista polaco- están dirigidos por empresarios y no por periodistas. La mayoría de los reporteros y medios ya no están interesados en comprender el mundo, sino en no dejarse ganar por la competencia, por ello, todos cubren los mismos acontecimientos sin prestar atención a lo que no es lo más espectacular del momento. ¿Espectáculo o información?

La nuestra es una aventura con rigor, una información que no renuncia al espectáculo pero que no se deja secuestrar por él. Y todo este esfuerzo, no lo olvidemos, lo estamos realizando desde instituciones públicas. En nuestro caso desde una televisión pública que apuesta, con recursos propios, por un producto arriesgado pero comprometido (5).

\section{Notas}

(1) Muñoz Ruiz E. y Plaza M. (2005) “Imágenes de la ciencia y la tecnología en España a través del espejo de la encuesta de percepción 2004". En "Percepción social de la ciencia y la tecnología en España 2004". FECYT: Madrid.

(2) Muñoz Ruiz E. y Plaza M. (2005) “Imágenes de la ciencia y la tecnología en España a través del espejo de la encuesta de percepción 2004". En "Percepción social de la ciencia y la tecnología en España 2004". FECYT: Madrid.

(3) La mayor parte de los documentales que se citan en este artículo están disponibles, online, en la 


\section{1/: Divulgación científica en televisión: - Rigor y entretenimiento}

CienciaTK del CSIC (www.cienciatk.csic.es). También pueden visionarse recurriendo a algunos enlaces que están recogidos en este post: http://elgatoeneljazmin.wordpress.com/2011/10/18/ciencia-en-accion/ (4) Kapuscinski, R. (2005). Los cínicos no sirven para este oficio. Madrid: Anagrama.

(5) Las cuatro series documentales producidas hasta la fecha se han seleccionado en numerosos certámenes especializados y también se han usado como material divulgativo-educativo en diferentes escenarios. Entre otros cabe citar: Jornadas sobre Documentales de Naturaleza de la Universidad de Valencia, Festival

\section{Divulgatio}

Internacional de Televisión para la Conservación y Divulgación de la Naturaleza (Telenatura), Muestra Internacional de Video Científico de Barcelona, Universidad de Córdoba, Universidad de Sevilla, Universidad Autónoma de Madrid, Universidad de Navarra, National Aviary (EEUU), Centro Nacional de Educación Ambiental, Parque de las Ciencias de Granada, Universidad Pompeu Fabra, Muestra Centroamericana de Cine y Video Ambiental (Costa Rica), Universidad de Buenos Aires, Centro Cultural de España en Buenos Aires, etc... 